

\title{
Action Mechanism of Superplasticizer in Consideration of Early Hydration of Cement
}

\author{
Yuta Ohtsuka $^{{ }^{*}}$, Daiki Atarashi ${ }^{2}$, Masahiro Miyauchi ${ }^{3}$ and Etsuo Sakai ${ }^{4}$
}

\begin{abstract}
Superplasticizers (SPs) are widely used in various concrete made in Japan to decrease the amount of water required for cement mixing. The use of hot-weather concrete is increasing. The number of interstitial cement phases, such as the aluminate and ferrite phases, will be increased to treat waste and byproducts in the cement industry. In such cases, early hydration will affect cement phase fluidity. Therefore, chemical admixtures, especially SPs, are gaining importance. It has been reported that changes in concrete fluidity with time are affected by SP molecular structure. However, the mechanisms of fluidity change is still not completely clarified. It is therefore necessary to study the interaction between cement and SPs. This study focuses on the mechanism of SP action, especially during early hydration. Polycarboxylate-based SP showed better fluidity retention than naphthalene sulfonate-based SP. This difference in fluidity-retaining performance is related to the amount of SP adsorbed per unit area. The fluidity reduction of cement paste with naphthalene sulfonate-based SP is attributed to a decrease in residual SP concentration in the liquid phase.
\end{abstract}

\section{Introduction}

Fresh concrete must be delivered to construction sites within $~ 90-120$ min after water addition at ready-mixed concrete plants. Concrete fluidity and its retention are thus important considerations. During the delivery period, the aluminate phase $\left(3 \mathrm{CaO} \cdot \mathrm{Al}_{2} \mathrm{O}_{3}\right)$ and the sulfate carrier generate ettringite $\left(3 \mathrm{CaO} \cdot \mathrm{Al}_{2} \mathrm{O}_{3} \cdot 3 \mathrm{CaSO}_{4} \cdot 32 \mathrm{H}_{2} \mathrm{O}\right)$, and alite $\left(3 \mathrm{CaO} \cdot \mathrm{SiO}_{2}\right)$ generates $\mathrm{Ca}(\mathrm{OH})_{2}$ and calcium silicate hydrate $\left(\mathrm{nCaO} \cdot \mathrm{SiO}_{2} \cdot \mathrm{mH}_{2} \mathrm{O}\right)$. These hydration reactions worsen cement paste fluidity.

Superplasticizers (SPs) are widely used in various concrete made in Japan to reduce the amount of water required for cement mixing. It has been reported that changes in concrete fluidity with time are affected by SP molecular structure. Based on surface science, our group discussed the action mechanisms of polycarboxylate (PC)-based SP and naphthalene sulfonate ( $\beta$-NS)-based SP. The effect of early hydration on dispersion function was also studied, using a new type of calorimeter that can analyze early hydration reactions (Kamio et al. 2011; Atarashi et al. 2008).

\footnotetext{
${ }^{1}$ Research Student, Tokyo Institute of Technology, Graduate School of Science and Engineering, Tokyo, Japan.

*Corresponding author, E-mail: ohtsuka.yuta@gmail.com ${ }^{2}$ Associate Professor, Shimane University, Interdisciplinary Graduate School of Science and Engineering, Matsue-shi, Shimane, Japan.

${ }^{3}$ Associate Professor, Tokyo Institute of Technology, Graduate School of Science and Engineering, Tokyo Japan.

${ }^{4}$ Professor, Tokyo Institute of Technology, Graduate School of Science and Engineering, Tokyo Japan.
}

With the 2009 revision of Japanese Architectural Standard Specification 5, which stipulates construction conditions (Architectural Institute of Japan 2009), the placement of concrete in temperatures exceeding $30^{\circ} \mathrm{C}$ is expected to increase in the near future. An increase in curing temperature will promote cement hydration (Uematsu et al. 2000; Yamada et al. 2002). Furthermore, changes in cement composition, such as increases in interstitial phases, may occur (Maruya et al. 2003). Because the interstitial phase reacts quickly during the early hydration stage, it is difficult for cements with increased interstitial phases to retain their fluidity. The SP action mechanism is more complex in these cases.

To date, fluidity change with time have been explained using a model (Suzue et al. 1981) in which the SP becomes buried in the hydrate and loses its dispersion function. Several studies investigated the relationship between fluidity change with time and the amount of adsorbed SP (Collepardi 1998; Hanehara and Yamada 1999; Yamada et al. 2000; Mizunuma 2013). However, the SP action mechanism during early hydration is still not completely clarified. Thus, in this study, we investigated this mechanism in further detail.

\section{Methods and materials}

\subsection{Materials}

Tables 1 and 2 show the physical and chemical properties and components of ordinary Portland cement (OPC) made by Japan Cement Association (Tokyo, Japan). The chemical composition was measured by use of X-ray fluorescence spectrometer. We used PC SP made by NOF Corporation (Tokyo, Japan) and $\beta$-NS SP made by Kao Corporation (Tokyo, Japan). Figure 1 shows the molecular structure of $\beta$-NS. The mean degree of polymerization of $\beta$-NS is 10 , quoted by the company. PC is a 
Table 1 Ordinary Portland cement (OPC) composition/mass\%.

\begin{tabular}{|c|c|c|c|c|c|c|c|c|c|c|c|}
\hline $\mathrm{SiO}_{2}$ & $\mathrm{Al}_{2} \mathrm{O}_{3}$ & $\mathrm{Fe}_{2} \mathrm{O}_{3}$ & $\mathrm{CaO}$ & $\mathrm{MgO}$ & $\mathrm{SO}_{3}$ & $\mathrm{Na}_{2} \mathrm{O}$ & $\mathrm{K}_{2} \mathrm{O}$ & $\mathrm{TiO}_{2}$ & $\mathrm{P}_{2} \mathrm{O}_{5}$ & $\mathrm{MnO}$ & $\mathrm{Total}$ \\
\hline 20.94 & 5.45 & 2.83 & 64.96 & 1.54 & 2.05 & 0.32 & 0.48 & 0.27 & 0.31 & 0.08 & 99.2 \\
\hline
\end{tabular}

Table 2 Character and mineral composition of OPC/mass $\%$.

\begin{tabular}{|c|c|c|c|c|c|}
\hline $\begin{array}{c}\text { Density } \\
\left(\mathrm{g} / \mathrm{m}^{3}\right)\end{array}$ & $\begin{array}{c}\text { Blaine's specific } \\
\text { surface area }\left(\mathrm{cm}^{2} / \mathrm{g}\right)\end{array}$ & $3 \mathrm{CaO} \cdot \mathrm{SiO}_{2}$ & $2 \mathrm{CaO} \cdot \mathrm{SiO}_{2}$ & $3 \mathrm{CaO} \cdot \mathrm{Al}_{2} \mathrm{O}_{3}$ & $4 \mathrm{CaO} \cdot \mathrm{Al}_{2} \mathrm{O}_{3} \cdot \mathrm{Fe}_{2} \mathrm{O}_{3}$ \\
\hline 3.16 & 3490 & 59 & 16 & 10 & 9 \\
\hline
\end{tabular}

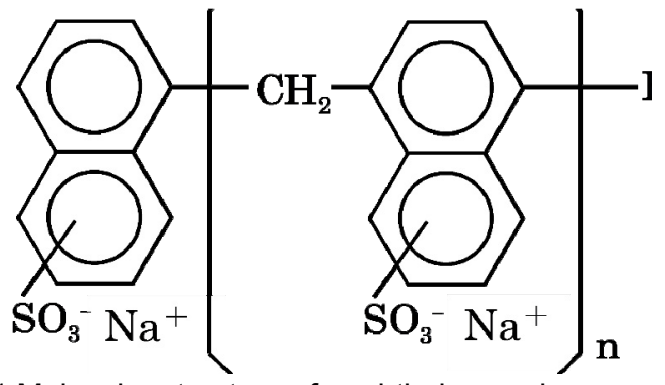

Fig. 1 Molecular structure of naphthalene sulfonate-based ( $\beta$-NS) superplasticizer.

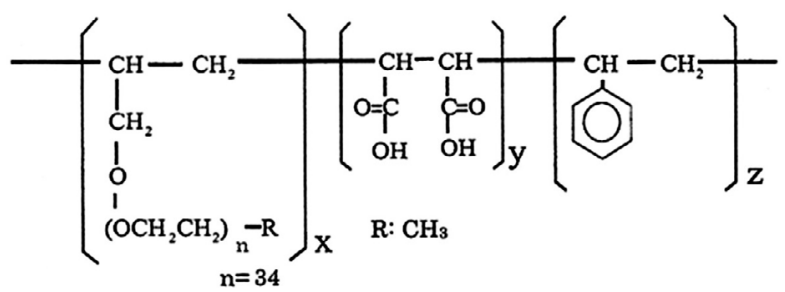

Fig. 2 Molecular structure of polycarboxylate (PC) SP.

copolymer that is synthesized with polyoxyethylene monoallyl monomethyl ether (X), maleic anhydride (Y) and styrene $(\mathrm{Z})$. The $\mathrm{X}: \mathrm{Y}: \mathrm{Z}$ ratio is $1: 1: 0.014$ and the mean degree of polymerization of the polyethylene oxide is 34 . Figure 2 shows the molecular structure of PC. The number-average molecular weight of $\mathrm{PC}$ is 23,100 , which is determined with GPC by use of PEG as a standard.

\subsection{Preparation}

SP and water were added to OPC with a water-cement ratio of 0.32 . The samples were mixed for $5 \mathrm{~min}$ by hand by using a rubber cup and a dispersing spoon. After allowing the samples to rest for a predetermined time, they were remixed for $1 \mathrm{~min}$. The SP dosage ranged from $\sim 0.1$ to 1.0 percent of cement mass in terms of pure content.

\subsection{Methods}

The apparent viscosity, amount of adsorbed SP, specific surface area, ignition loss and cumulative heat liberation were measured for each sample. The apparent viscosity was measured using a stress-controlled co-axial cylinder rotation viscometer (Thermo Fisher Scientific K.K., Kanagawa, Japan, Haake MARS3 Z41 TI). The shear stress was changed linearly from 0 to $200 \mathrm{~Pa}$ and back to $0 \mathrm{~Pa}$, and the apparent viscosity at $200 \mathrm{~Pa}$ was set as a measure of fluidity.
The amount of adsorbed SP was calculated from the carbon concentration, which was measured by total organic carbon analysis (Shimadzu Corporation, Kyoto, Japan, TOC-L CSH). To measure the carbon concentration, the liquid phase was separated centrifugally from the samples at $1000 \mathrm{rpm}$ for $10 \mathrm{~min}$ using a refrigerated centrifuge (Kokusan Corporation, Tokyo, Japan, H-1500DR) with a centripetal acceleration of 35,000 $\mathrm{m} / \mathrm{s}^{2}$.

To measure the specific surface area, samples were dried under vacuum for 1 day after cement paste hydration was stopped using acetone at $20^{\circ} \mathrm{C}$. The specific surface area of the dried samples was measured by BET method by $\mathrm{N}_{2}$ adsorption using a surface area analyzer (Shimadzu, Kyoto, Japan, GeminiV2380) after keeping the samples in $\mathrm{N}_{2}$ gas flow for 3 hours at $40^{\circ} \mathrm{C}$. The ignition loss to $1000^{\circ} \mathrm{C}$ of the dried samples was measured using a thermogravimetric-differential thermal analyzer simultaneous measuring instrument (Bruker AXS K.K., Kanagawa, Japan, TG-DTA2000S).

We measured the cumulative heat liberation of cement with or without SP 95 min after mixing using a conduction calorimeter (Tokyo Riko Co. Ltd, Tokyo, Japan, MPC-11).

The curing and measurement temperatures were $20 \pm$ $1^{\circ} \mathrm{C}$ and $35 \pm 1^{\circ} \mathrm{C}$, respectively.

\section{Results and discussion}

\subsection{Viscosity change with time}

Figures 3 and 4 show the viscosity change with time for the $\beta$-NS and PC SP cement paste at $20^{\circ} \mathrm{C}$. The PC SP cement paste viscosity is constant with time. The apparent viscosity of the $\beta$-NS SP cement paste increases with time; i.e., the fluidity worsens. For $\beta$-NS dosage of 0.57 mass $\%$, the viscosity increases notably. On the other hand, for PC SP dosage of 0.3 mass $\%$, the viscosity is constant with the lapse of time. It should be noted that the viscosity decreases for the smaller dosage of PC SP. It is inferred that this phenomenon results from inhibition of adsorption by sulfate ion at the initial stage of hydration. (Nakajima et al. 2004) Then the concentration decreases with time and the amount of adsorption increases. When the viscosity is $500 \mathrm{mPa} \cdot \mathrm{s}$ ( $5 \mathrm{~min}$ after mixing), the $\beta-\mathrm{NS}$ SP and PC SP dosages are 0.57 mass $\%$ and 0.3 mass $\%$, respectively. The change in sample viscosity with time was determined according to the SP dosage, and the difference in fluidity retention performance of each SP was confirmed. 


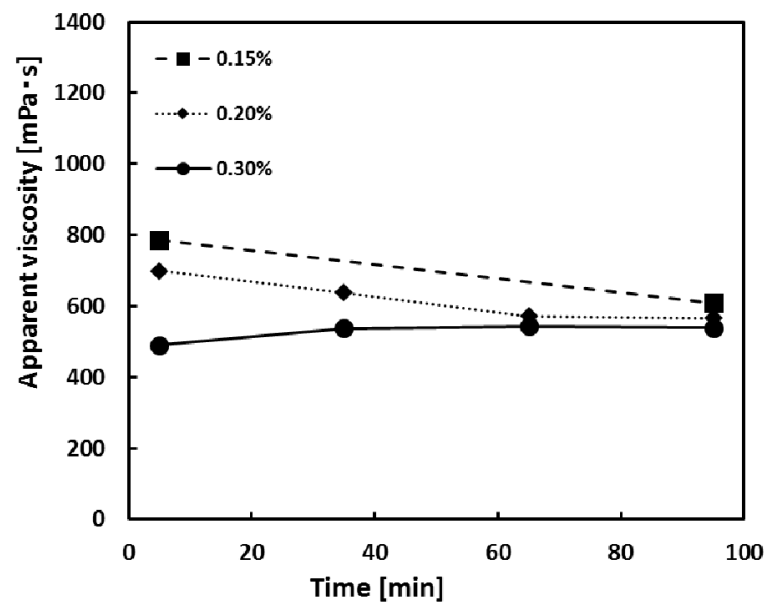

Fig. 3 Change of cement paste apparent viscosity with time (PC SP).

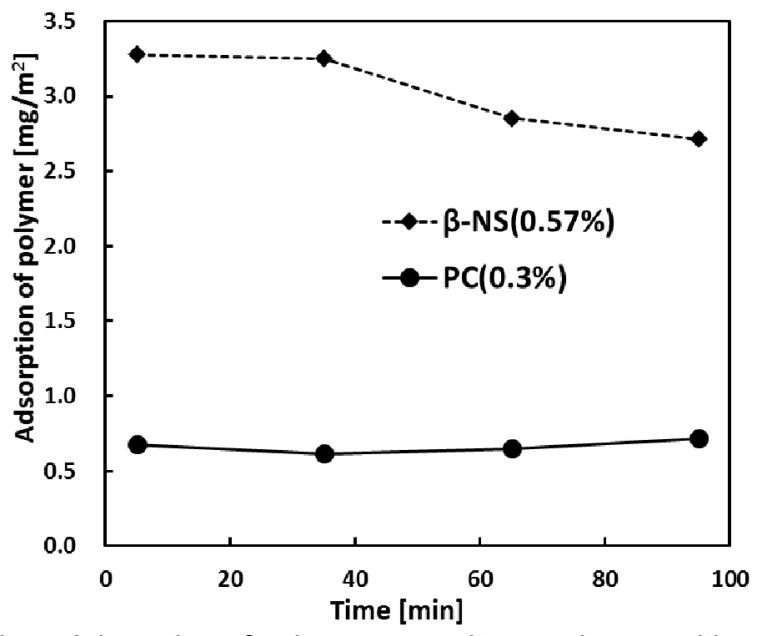

Fig. 5 Adsorption of polymer per unit area change with time.

\subsection{Amount of SP adsorbed}

Figure 5 shows the temporal change in SP adsorbed per unit area, where the initial apparent viscosity of both samples is $500 \mathrm{mPa} \cdot \mathrm{s}$. Although the amount of PC SP adsorbed per unit area is constant, the amount of $\beta$-NS SP adsorbed decreases $35 \mathrm{~min}$ after water addition. This behavior corresponds to a decrease in fluidity. Figure 6 presents the relationship between the amount of SP adsorbed per unit area and the apparent viscosity at various time $(5,35,65$ and $95 \mathrm{~min})$ and with various dosage $(0.57,0.75$ and 1.00 mass\%). The trendline in Fig. 6 is made as an exponential trendline. The apparent viscosity increases with a decreasing amount of $\beta$-NS adsorbed per unit area. The $0.5-\mathrm{mg} / \mathrm{m} 2$ decrease in amount adsorbed per unit area leads to a notable increase in apparent viscosity. Therefore, the increase in apparent viscosity results from a reduction in the amount of SP adsorbed per unit area. These data show that fluidity is largely affected by the amount of SP adsorbed per unit area. We discuss the cause of this reduction in the amount of SP adsorbed in the following section.



Fig. 4 Change of cement paste apparent viscosity with time ( $\beta$-NS SP).

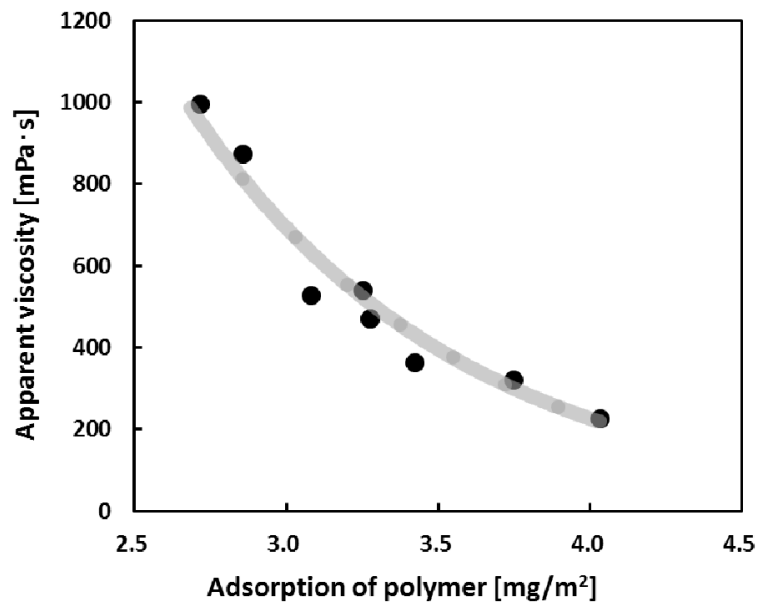

Fig. 6 Relationship between the adsorption of polymer and paste viscosity ( $\beta$-NS SP).

\subsection{Adsorption isotherm}

SP adsorption on cement particles often roughly follows the Langmuir adsorption model (Yamada et al. 2001). Results were fitted using the Langmuir equation (Eq. (1)), which is based on the ideas of single-layer adsorption and dynamic equilibrium. The adsorption isotherm is determined from the saturated amount of SP adsorbed $\left(V_{\mathrm{m}}\right)$ and the adsorption equilibrium constant $(K)$. A larger $K$ corresponds to a strong affinity for the surface.

$$
\frac{C}{V}=\frac{1}{K V_{\mathrm{m}}}+\frac{C}{V_{\mathrm{m}}}
$$

where $C$ is concentration in solution, $V$ is adsorption amount of SP, $K$ is adsorption equilibrium constant and $V_{\mathrm{m}}$ is saturated adsorption amount of SP.

Figure 7 shows the adsorption isotherm of each SP. The amount of adsorbed polymer was measured $95 \mathrm{~min}$ after mixing. Fitting was performed using the measurement values (five points for each curve) and assuming that the adsorption of SP follows the Langmuir adsorption model. The correlation coefficients of $\beta$-NS and PC 


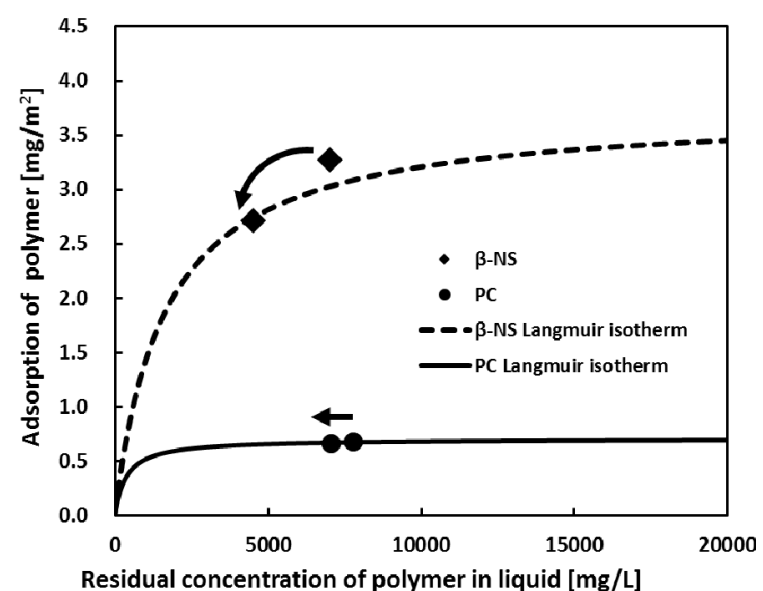

Fig. 7 Adsorption isotherms of SPs on cement (95 min) (Correlation coefficients of $\beta$-NS and PC SP are 0.999 and 0.998).

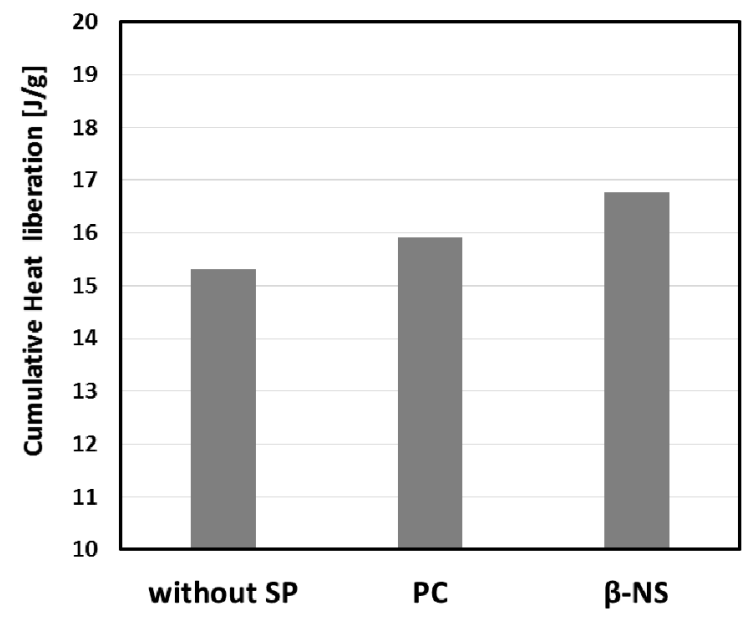

Fig. 9 Cumulative heat liberation 95 minutes after mixing.

SP are 0.999 and 0.998 , respectively. The amount adsorbed changed with time as shown in Fig. 5. Early hydration results in an increase in the specific surface area, and SP is adsorbed onto the surface of the hydrated products. The residual concentrations of $\beta$-NS and PC SP decrease as a result. The concentration of PC SP changes in the saturated region while that of the $\beta$-NS SP changes from the saturated region to the unsaturated region. The decrease in the residual concentration of $\beta$-NS SP, and not PC SP, decreases the amount adsorbed. This results from the different forms of the adsorption isotherms (i.e., the adsorption power).

\subsection{Change in adsorption isotherm with time}

Cement causes hydration reaction immediately after mixing with water, generating various hydrates and increasing the specific surface area. Cement particles possess various types of surfaces, which change continually. Therefore, the adsorption isotherms in Fig. 7 also change with time. Figure 8 shows the change in the specific surface area of SP cement. The specific surface area of the cement paste with $\beta$-NS SP increases more than that of cement paste with PC SP. $\beta$-NS SP therefore

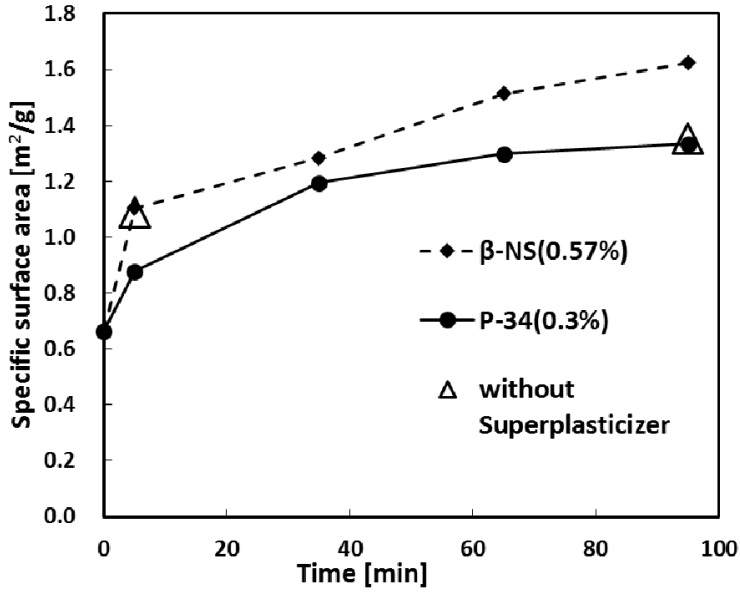

Fig. 8 Change in specific surface area of cement with time.

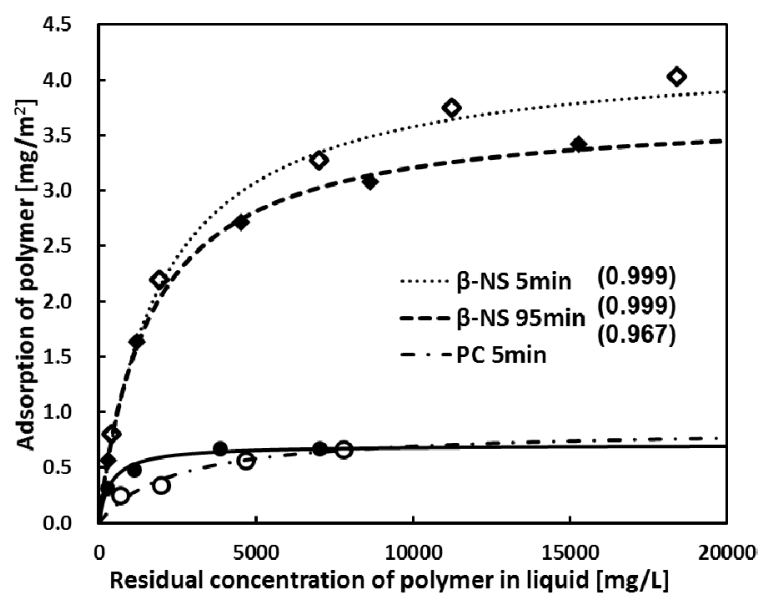

Fig. 10 Adsorption isotherms of SPs on cement (5 and 95 min) (Correlation coefficients in brackets).

accelerates cement hydration. The amount of bound water in the hydrated cement with either SP is calculated from the ignition loss data. The ignition losses of hydrated cement with $\beta$-NS and PC SP are 3.30 mass $\%$ and 2.40 mass $\%$, respectively. These results correspond with those of the specific surface area. Furthermore, Fig. 9 shows the cumulative heat liberation of each sample (cement without SP, with PC SP, and with $\beta$-NS SP) 95 min after mixing. Kim et al. reported that the amount of generated ettringite increases by adding $\beta$-NS SP to cement paste. (Kim et al. 2000) These results also support the idea that the $\beta$-NS SP accelerates cement hydration.

Figure 10 shows the adsorption isotherms of SP, 5 and 95 min after mixing. The adsorption isotherm of $\mathrm{PC}$ does not show large differences; however, that of $\beta$-NS does. The amount of $\beta$-NS SP adsorbed per unit area decreases overall. The adsorption behavior of $\beta$-NS SP on the hydrate generated in $95 \mathrm{~min}$ is therefore different from that on nonhydrated cement. It might be possible that hydrates have less adsorption sites than nonhydrated cement. Hence, the adsorption behavior of SP, especially on hydrate, should be considered. Some researchers also argue that SPs can alter the size of hydrates and make 


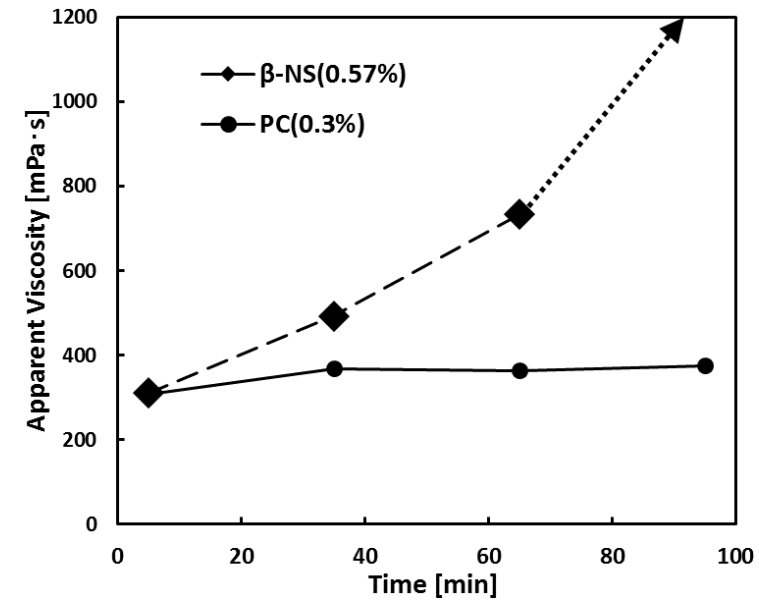

Fig. 11 Change of cement viscosity with time $\left(35^{\circ} \mathrm{C}\right)$.

morphological change in hydrates. (Dalas et al. 2015) For example, $\beta$-NS SP is said to be strong morphological catalyst for ettringite, on the other hand, PC SP does not have much impact. (Plank and Hirsch 2003) These effects can also be related to the decrease of adsorption of $\beta$-NS SP per unit area, observed in our experiment. This should also be investigated more in detail.

\subsection{Fluidity at $35^{\circ} \mathrm{C}$}

We examined the fluidity of SP cement paste at $35^{\circ} \mathrm{C}$. Figure 11 shows the change in viscosity with time of the cement paste with $\beta$-NS and PC SP at $35^{\circ} \mathrm{C}$. The viscosity of the cement paste with $\beta$-NS SP, 95 min after mixing, is indicated by an arrow. This means that the viscosity is too high to measure under the same conditions. Similar to the case at $20^{\circ} \mathrm{C}$, the cement paste with $\mathrm{PC}$ exhibits viscosity that is constant with time. The apparent viscosity of the cement paste with $\beta$-NS SP increases with time; i.e., the fluidity worsens.

Figure 12 shows the temporal change in the amount of SP adsorbed per unit area. Although the amount of $\mathrm{PC}$ adsorbed is constant with time, the amount of $\beta$-NS adsorbed decreases. The decrease in fluidity results from a reduction in the amount of SP adsorbed per unit area. However, the hydration reaction is accelerated at $35^{\circ} \mathrm{C}$ compared with that at $20^{\circ} \mathrm{C}$, and the SP mechanisms appear more complicated. It is therefore necessary to examine these mechanisms in further detail; for example, adsorption behavior of each SP on hydrates, such as $\mathrm{Ca}(\mathrm{OH})_{2}$ and calcium silicate hydrate, should be investigated. The change in viscosity of solvent (water) should also be considered.

\section{Conclusion}

The effects of two types of SP on changes in cement paste fluidity with time were studied in relation to the amount of SP adsorbed during early hydration. The following conclusions are made.

(1) Differences exist in the fluidity retaining performance of $\beta$-NS and PC SPs. PC SP performs better than $\beta$-NS SP.

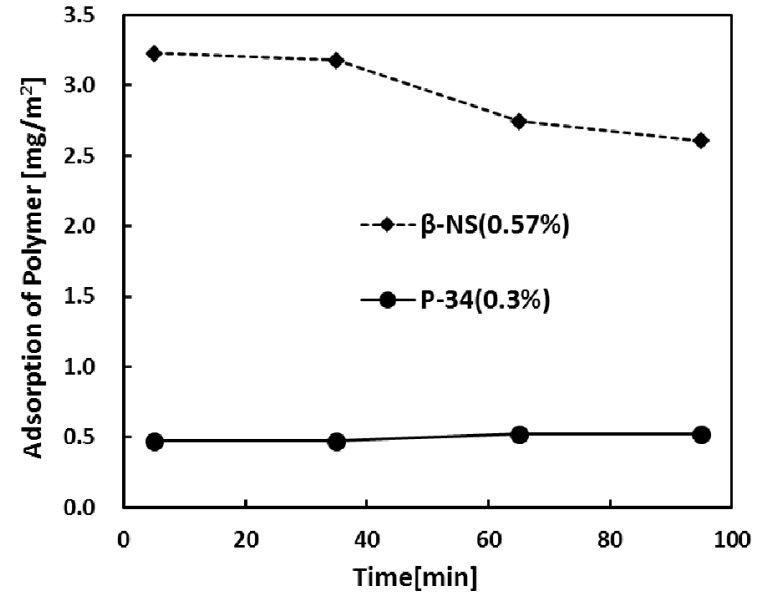

Fig. 12 Adsorption of polymer per unit area versus time $\left(35^{\circ} \mathrm{C}\right)$.

(2) When the cement paste fluidity is reduced, the amount of polymer adsorbed per unit area also decreases. Changes in fluidity 5 95 minutes after mixing are largely affected by the amount of adsorbed SP per unit area. This relationship is also correct when the changes in fluidity with time is investigated.

(3) The connection between the residual concentration of SP in the liquid and the amount of adsorbed SP per unit area is clear from the Langmuir adsorption model.

(4) The amount of binding water, specific surface area, and cumulative heat liberation of the hydrated cement with $\beta$-NS SP are larger than those of PC SP. $\beta$-NS SP accelerates hydration.

(5) Differences in the adsorption isotherms of each SP were determined. PC SP adsorption becomes saturated earlier than $\beta$-NS SP adsorption. The decrease in the residual concentration of $\beta$-NS SP, and not PC SP, decreases the amount adsorbed. This decrease worsens the fluidity.

(6) The adsorption isotherm of the PC SP does not show large differences between 5 and 95 min after mixing, however, that of $\beta$-NS SP does. The adsorption behavior of SP on hydrates should therefore be considered.

\section{Acknowledgment}

The authors would like to express their gratitude to NOF Corporation for providing the superplasticizers.

\section{References}

Architectural Institute of Japan, (2009). "Japanese Architectural Standard Specification 5." (in Japanese)

Atarashi, D., Sakai, E., Song, Y. and Takeuchi, T., (2008). "Fluidity and heat liberation of cement paste containing comb-type superplasticizer." Cement Science and Concrete Technology, 62, 27-32. (in Japanese)

Collepardi, M., (1998). "Admixtures used to enhance placing characteristics of concrete." Cement and 
Concrete Composites, 20(2), 103-112.

Dalas, F., Pourchet, S., Rinaldi, D., Nonat, A., Sabio, S. and Mosquet, M., (2015). "Modification of the rate of formation and surface area of ettringite by polycarboxylate ether superplasticizers during early $\mathrm{C}_{3} \mathrm{~A}_{-}-\mathrm{CaSO}_{4}$ hydration." Cement and Concrete Research, 69, 105-113.

Hanehara, S. and Yamada, K., (1999). "Interaction between cement and chemical admixture from the point of cement hydration, absorption behaviour of admixture, and paste rheology." Cement and Concrete Research, 29(8), 1159-1165.

Kamio, T., Atarashi, D., Maruya, E. and Sakai, E., (2011). "Fluidity control of high aluminate phase cement paste: Effect of calcium oxide and limestone powder." Cement Science and Concrete Technology, 65, 14-19. (in Japanese)

Kim, B., Jiang, S., Jolicoeur, C. and Aitcin, P., (2000). "The adsorption behavior of PNS superplasticizer and its relation to fluidity of cement paste." Cement and Concrete research, 30(6), 887-893.

Maruya, E., Ohsaki, M., Sakai, E. and Daimon, M., (2003). "Influence of $\mathrm{C}_{3} \mathrm{~A}$ and calcium sulfate on the fluidity of cement increasing interstitial phase." Cement Science and Concrete Technology, 57, 38-43. (in Japanese)

Mizunuma, T., (2013). "High-range water reducing agents and the development of high-range water reducing AE agents." Cement and Concrete, 793, 42-48. (in Japanese)

Nakajima, Y. and Yamada, K., (2004). "The effect of the kind of calcium sulfate in cements on the dispersing ability of poly $\beta$-naphthalene sulfonate condensate superplasticizer." Cement and concrete research, 34(5), 839-844.

Plank, J. and Hirsch, C., (2003) "Superplasticizer adsorption on synthetic ettringite." ACI Special Publication 217.

Suzue, S., Okada, E. and Hattori, K., (1981). "Adsorption behavior of high-range water reducing on cement." Cement Science and Concrete Technology, 35, 10-19. (in Japanese)

Uematsu, C., Nawa, T., Kinoshita, M. and Ichibouji, H., (2000). "The Influence of temperature on interaction between cement and polycarboxylate-based superplasticizer." Cement Science and Concrete Technology, 54, 660-665. (in Japanese)

Yamada, K., Takahashi, T., Hanehara, S. and Matsuhisa, M., (2000). "Effects of the chemical structure on the properties of polycarboxylate-type superplasticizer." Cement and concrete research, 30(2), 197-207.

Yamada, K., Ozu, H. and Yano, M., (2001). "The adsorbing behavior of polycarboxylate-type superplasticizer on cement hydrates and the effects of sulfonate ion." Cement Science and Concrete Technology, 55, 27-34. (in Japanese)

Yamada, K., Ozu, H. and Yano, M., (2002). "Temperature dependence of the dispersing performance of poly-beta-naphthalene sulfonate superplasticizer." Cement Science and Concrete Technology, 56, 521-528. (in Japanes) 